\title{
Cross-cultural adaptation of the Safety Attitudes Questionnaire - Short Form 2006 for Brazil ${ }^{1}$
}

\author{
Rhanna Emanuela Fontenele Lima de Carvalho²
}

Silvia Helena De Bortoli Cassiani ${ }^{3}$

The objective of this study was to perform a cross-cultural adaptation of the Safety Attitudes Questionnaire - Short Form 2006 for Brazil. The instrument was applied in six hospitals in three regions of Brazil. Content, face, and construct validity was performed. Analysis of the instrument's reliability was performed by verifying the items' internal consistency through Cronbach's alpha. The sample was composed of 1301 professionals working in clinical and surgical wards of six hospitals. Confirmatory analysis showed that the model including 41 items was satisfactory. The Portuguese version presented an alpha of 0.89 . The item-total correlations among the domains were moderate to strong, except for the domain Stress Recognition. We concluded that the instrument's version adapted to Portuguese and applied in our sample is valid and reliable.

Descriptors: Translating; Validation Studies; Organizational Culture.

\footnotetext{
${ }^{1}$ Paper extracted from Doctoral Dissertation "Adaptação transcultural do Safety Attitudes Questionnaire para o Brasil - Questionário de Atitudes de Segurança" presented to Escola de Enfermagem de Ribeirão Preto, Universidade de São Paulo, WHO Collaborating Centre for Nursing Research Development, Brazil. This research was supported by Fundação de Amparo à Pesquisa do Estado de São Paulo (FAPESP), process \# 09/16231-6 and Organização Mundial da Saúde (OMS), process \# PS08041.

2 RN, PhD.

${ }^{3}$ PhD, Full Professor, Escola de Enfermagem de Ribeirão Preto, Universidade de São Paulo, WHO Collaborating Centre for Nursing Research Development, Brazil.
} 


\title{
Questionário Atitudes de Segurança: adaptação transcultural do Safety Attitudes Questionnaire - Short Form 2006 para o Brasil
}

O objetivo deste estudo foi realizar a adaptação transcultural do Safety Attitudes Questionnaire - Short Form 2006 para o Brasil. O instrumento foi aplicado em seis hospitais de três Regiões do Brasil. Foi realizada a validade de conteúdo, face e de construto. A análise da confiabilidade do instrumento foi realizada por meio da análise da consistência interna dos itens por meio do alfa de Cronbach. A amostra do estudo foi composta por 1.301 profissionais das enfermarias clínicas e cirúrgicas de seis hospitais. A análise confirmatória mostrou que o ajuste do modelo final dos 41 itens foi considerado satisfatório. Aversão do instrumento em Português apresentou alfa de 0,89. As correlações item/total entre os domínios foram consideradas de moderada a forte, com exceção do domínio percepção do estresse. Conclui-se, portanto, que a versão do instrumento adaptada para o Português é considerada válida e confiável nesta amostra.

Descritores: Tradução (Processo); Estudos de Validação; Cultura Organizacional.

\section{Cuestionario de actitudes de seguridad: adaptación transcultural del Safety Attitudes Questionnaire - Short Form 2006 para Brasil}

\begin{abstract}
El objetivo de este estudio fue el de adaptación transcultural del cuestionario Actitudes de Seguridad - Short Form 2006 para Brasil. Métodos: El instrumento fue aplicado en seis hospitales en tres regiones del Brasil. Se realizó la validez de contenido, la cara y la construcción. El análisis de confiabilidad del instrumento se realizó mediante el análisis de la consistencia interna de los ítems a través de alfa de Cronbach. Resultados: La muestra del estudio fue compuesto por 1.301 profesionales en salas clínicas y cirugía. El análisis confirmatorio mostró que el ajuste del modelo final de los 41 ítems fue satisfactorio. La versión en portugués del instrumento mostró un alfa de 0,89 . Las correlaciones ítem-total entre los dominios se consideran entre moderados y fuertes, con la excepción de dominio Percepción del Estrés. Conclusión: Se concluye, que la versión adaptada del instrumento al portugués se considera válida y fiable en la muestra.
\end{abstract}

Descriptores: Traducción (Proceso); Estudios de Validación; Cultura Organizacional.

\section{Introduction}

The use of scales to measure the safety climate in healthcare organizations has been implemented since the early 1980's. This way of measuring the safety climate is an important method to assess the quality of care provided to patients and scales can be applied before and after the implementation of interventions, such as staff training and stress minimizing activities.

Safety climate is related to unsafe practices, with an increase in injuries among professionals ${ }^{(1)}$. Among the most widely used instruments to analyze safety climate, only two (CSS-Safety Culture Survey and SAQ - Safety Attitudes Questionnaire) show a positive association between the obtained scores and improvements in patient care delivery, although the SAQ is more sensitive to evaluate individual safety attitudes than the $\operatorname{CSS}^{(1)}$. The results of this scale can also be compared with patient safety indicators, such as hospital infection rates, pressure ulcer rates and length of hospital stay ${ }^{(2)}$. That is, the higher the score obtained on the scale, the shorter the patients' length of stay at the unit and the lower the number of hospital infections.

Before applying any scale or questionnaire, however, researchers need to ensure the instruments' validity. Another important aspect is the cultural context in which these scales will be used. Before implementing any instruments, it is essential to culturally adapt them to the country or city where they will be applied(2).

Based on these recommendations, we aimed to provide for the first Brazilian scale, capable of assessing the safety climate based on professionals' perception. The scale chosen was the Safety Attitudes Questionnaire Short Form 2006, because it presents good psychometric 
properties (Cronbach 0.7 to 0.8 ) and is the assessment tool most commonly used in the United States, UK and Australia(3). This scale is capable of providing information about factors that need to be implemented within the institution and influence the safety climate, such as teamwork, job satisfaction and working conditions.

\section{Method}

This is a methodological and cross-sectional study with a quantitative approach. In this study, we performed content, face and construct validity.

\section{The instrument}

The Safety Attitudes Questionnaire - Short Form 2006 was created to evaluate how professionals perceive patient safety issues. The instrument has 41 questions that attempt to measure perceptions of safety climate through six domains: Teamwork Climate, Job Satisfaction, Perception of the Management Unit and the Hospital, Working Conditions and Stress Recognition ${ }^{(4)}$. Answers to questions follow a five-point Likert scale: disagree strongly (A), disagree slightly (B), neutral (C), agree slightly (D), agree strongly and (E) not applicable.

The instrument is divided into two parts: the first part is composed of 41 questions that address the six domains; the second part collects data from professionals (gender, profession, and years in specialty).

The final score of the instrument ranges from 0 to 100 , where zero represents the worst and 100 the best perception of the safety climate. Values are considered positive when the total score is equal to or higher than 75. The score is ordered as follow: disagree strongly $(A)$ equals 0 points, disagree slightly (B) 25 points, neutral (C) 50 points, agree slightly (D) 75 points and agree strongly (E) 100 points. Scores are counted as follows: Initially, the questions are recoded, i.e. the answer "I totally disagree" becomes "totally agree", and so on. Then, the questions are grouped per domain. Finally, responses to the questions in each domain are added up and divided by the number of questions in each area. For example, Stress Recognition is composed of four questions. If the participant's answers to each question are, respectively, neutral, agree slightly, neutral and disagree slightly, the score for this area will be: $(50+75+50+25) / 4=50$.

\section{Local data collection}

After the translation process of the Safety Attitudes Questionnaire, we proceeded with the application of the questionnaires to evaluate the scale's psychometric properties, reliability and validity. The instrument was administered at six public tertiary hospitals in three regions of Brazil.

\section{Team Training}

Before initiating data collection, technical visits were conducted at each hospital in order to learn about the institutions and clarify the importance of the study to the hospital managers.

A coordinator and two research assistants were appointed to each hospital. All coordinators are members of the same research group and were familiar with the studied hospitals. The project coordinators and researchers selected the research assistants. To be chosen, research assistants should be health professionals and have knowledge of the routine at the hospitals where the research would be conducted.

The research coordinators were responsible for meeting with the managers and the staff, study the logistics, guide the research assistants, and distributing and collecting the questionnaires. The research assistants were responsible for applying the questionnaire to the professionals.

Training was implemented at each research center and took one week. The training was aimed at familiarizing the research assistants with the instrument, address potential doubts that could arise during the completion of the scale, and train them to approach the professionals.

\section{Participants}

The study population consisted of all professionals working in the clinical and surgical wards of the six health facilities chosen for the study. Professionals should meet the following inclusion criteria to participate: having worked at the hospital for at least one month and working in the surgical or clinical area at least 20 hours per week. Two to ten respondents per items are required to perform the factor analysis; ten respondents were considered in this study ${ }^{(5)}$.

\section{Data Collection}

Before data collection, a meeting was held with the management of each unit to explain the importance and objectives of the study, as well as the technical procedures to carry out the research. Data collection was conducted from July to December 2010.

The professionals were addressed at the workplace and, at times they were available to participate in the study. Some instruments were handed over to be answered and returned within a pre-established return date. Each employee received two copies of the informed consent 
term to sign, one of which was returned to the researcher. Those who agreed to participate received an envelope, containing a color copy of the scale, along with a pencil and an eraser required to fill out the questionnaire.

Before completing the questionnaire, the researchers provided each professional with explanations about the study objectives, how to complete the instrument, and the approximate time to complete the scale $(\approx 15 \text { minutes })^{(3)}$.

\section{Evaluation of psychometric properties}

Content, face and construct validity was verified in this study. A panel of judges conducted the content validity, face validity was conducted by a group of professionals during the pre-test, and construct validity was assessed through exploratory and confirmatory factor analysis.

The following steps were followed for the translation and validation of the instrument: translation, synthesis of translations, back translation to the source language (back translation), synthesis of back translation, review by a panel of judges, pre-test, submission and evaluation of reports by the instrument authors and psychometric evaluation ${ }^{(6)}$. Before starting the study, the authors of the instrument gave their permission to translate and validate the instrument.

Two independent bilingual translators translated the instrument into Portuguese. After this process, a synthesis of the two versions was developed to obtain a consensus version. The third phase included the translation of the instrument back to the source language (back translation). This phase involved two bilingual translators, one of them fluent in the target language and the other a native English speaker.

After the translation phase (original and back translation), a panel of nine judges evaluated all versions generated during the translation process and back translation and the original questionnaire to produce a final version, modified and adapted to guarantee a faithful replicate to the same language of its intended use(6).

Nine judges were chosen from various specialties (psychologists, doctors and nurses) and from different regions of Brazil, aiming to assess the instrument's conceptual, semantic, idiomatic and cultural equivalence. The judges should meet at least one of three criteria to be chosen: knowledge of the English language; experience in the field of patient safety; or previous participation in research involving the translation and validation of scales.

The items were considered equivalent when $80 \%$ of the judges agreed on all equivalences. When the item had a disagreement rate of $80 \%$ or higher, the author and orientador discussed the issues and, in most cases, the judges' suggestions were followed.

All documents generated in each phase of the scale translation and suggested changes for the cultural adaptation were sent to the author of the scale for approval.

Following the evaluation of the final version by the scale author, a pre-test (face validity) was developed with ten professionals from the studied hospitals, in order to assess whether the instrument was comprehensible, as well as to estimate the time spent for its completion. Secondary-level professionals took longer to answer the questionnaire than those at the professional level. The average time to complete the questionnaire was ten minutes. The secondary-level professionals also showed more difficulties to interpret the questions, which explains the delay to complete the instrument.

All reports concerning each stage of the translation process and the final instrument were sent to the scale author. The author approved the final version.

For the analysis of psychometric properties, it is also important to analyze the reliability of the measuring instrument. The instrument was subject to reliability analysis, using Cronbach's alpha for the scale as a whole and for each domain. This indicator reflects the items' degree of covariance. Its value ranges from zero to one. The higher the value, the greater the internal consistency and coherence among the proposed items. Alpha coefficients around 0.8 are considered reasonable, while those under seven are insufficient to demonstrate the instrument's reliability ${ }^{(7)}$.

Data were entered into an Excel $^{\circledR}$ spreadsheet for further processing and analysis. Data processing was performed using Statistical Package for Social Science (SPSS) version 15.0. Factor analysis was performed using the statistical software R.

\section{Ethical issues}

The study received approval from the ethics committees at the six institutions studied and by the ethics committee of the World Health Organization, as the project is funded by this institution. Before applying the scale, all professionals who agreed to participate in the study received informed consent terms and confidentiality was guaranteed.

\section{Results}

\section{Cultural adaptation of the Safety Attitudes Questionnaire - Short Form 2006 for Brazil}

After the translation of the Safety Attitudes Questionnaire-Short Form 2006, the psychometric properties, reliability and validity were assessed. Of the 1506 questionnaires distributed, 1301 returned (86\%). 
The return rate of the questionnaires ranged from $40 \%$ to $94 \%$ among the study hospitals.

With regard to the characteristics of the study subjects from all six hospitals: female gender predominated; technicians and registered nurses were the professionals who most frequently filled out the questionnaire, followed by physicians; $25.3 \%$ of the participants had between 5 and 10 years of experience in the specialty (Table 1 ).

Table 1- Characteristics of the professionals studied. Brazil, 2011

\begin{tabular}{|c|c|c|}
\hline Characteristics & Frequency & $\%$ \\
\hline \multicolumn{3}{|l|}{ Gender } \\
\hline Male & 297 & 22.8 \\
\hline Female & 968 & 74.4 \\
\hline Missing data & 36 & 2.8 \\
\hline \multicolumn{3}{|l|}{ Years in specialty } \\
\hline$<6$ months & 99 & 7.6 \\
\hline 6 to 11 months & 88 & 6.8 \\
\hline 1 to 2 years & 197 & 15.1 \\
\hline 3 to 4 years & 184 & 14.1 \\
\hline 5 to 10 years & 329 & 25.3 \\
\hline 11 to 20 years & 222 & 17.1 \\
\hline 21 years or more & 145 & 11.1 \\
\hline Missing data & 37 & 2.8 \\
\hline \multicolumn{3}{|l|}{ Professionals } \\
\hline Physicians and resident Physicians & 178 & 13.6 \\
\hline Registered nurses & 213 & 16.4 \\
\hline Nurse technicians & 731 & 56.2 \\
\hline Physiotherapists & 36 & 2.8 \\
\hline Admin Support & 36 & 2.8 \\
\hline Others & 97 & 7.4 \\
\hline Missing data & 10 & 0.8 \\
\hline Total & 1301 & 100 \\
\hline
\end{tabular}

Before the quantitative analysis of results related to the instrument, we performed a descriptive analysis of missing data and atypical responses.

\section{Study of missing data and atypical responses}

When the total of missing data exceeded $5 \%$ per variable, the t-test was performed. This test was performed to identify whether the unanswered questions would influence the analysis ${ }^{(8)}$. Missing data percentages higher than $5 \%$ were observed for all questions on the perception of Hospital Management: Q.24A (7.8\%), Q.25A (8.8\%), Q.26A (8 2\%), Q.27A (8.1\%), Q.28A (8.5\%).

The t-test was then conducted for these questions only. Two groups were formed to compare the averages: one group of missing data and another group without missing data. The significance level was set at 0.05 . The t-test showed that the behavior of the missing data for these questions could not be regarded as random. Therefore, it was not possible to use data correction methods.

Thus, we decided to exclude 95 instruments with missing data in all questions on the Perception of Hospital Management (Q.24A, Q.25A, Q.26A, Q.27A, Q.28A). Analysis of psychometric properties was performed for 1206 out of the 1301 completed instruments. For the instrument's remaining questions, in which missing data were considered random, and could therefore be corrected, missing data were completed by averaging the questions in each domain ${ }^{(9)}$.

No questionnaire was excluded because of atypical responses that tended to extremes. The item "not applicable" was considered as having a semantic meaning in the Portuguese version, but it was not included in the questionnaire average or score calculations.

\section{Reliability and construct validity}

After the recoding of reverse items, the score was calculated for each domain, following the formula: $(m-1) \times 25$, where $m$ is the average of the items of the domain in question, with a possible range from 0 to 100 . Values greater than 75 express strong agreement among the professionals on the patient safety questions.

The reliability analysis of the SAQ Portuguese version was performed by analyzing the internal consistency of its items through Cronbach's alpha, both for the total scale and its domains.

The study results show an alpha coefficient of 0.89 for the Portuguese version (Table 2). The analysis by area showed that five of its domains presented an alpha above 0.70 . The domain of Perception Management Unit revealed the best internal consistency (0.79) and the areas Working Conditions and Teamwork Climate the lowest coefficient (0.65).

Table 2 presents the mean and median total score of the questionnaire and per domain.

Table 2 - Descriptive analysis of the Safety Attitudes Questionnaire- Portuguese version. Brazil, 2011

\begin{tabular}{|c|c|c|c|c|c|}
\hline Domains & $\begin{array}{l}\text { No. of } \\
\text { item }\end{array}$ & $\begin{array}{l}\text { Cronbach's } \\
\text { alpha }\end{array}$ & Median & Average & SD \\
\hline SAQ total & 41 & 0.89 & 75 & 61.5 & 33.4 \\
\hline Teamwork climate & 6 & 0.65 & 75 & 69.46 & 29.9 \\
\hline Safety climate & 7 & 0.67 & 75 & 60.5 & 32.3 \\
\hline Job satisfaction & 5 & 0.77 & 75 & 77.66 & 27.8 \\
\hline Stress recognition & 4 & 0.78 & 87.5 & 71.51 & 33.4 \\
\hline \multicolumn{6}{|l|}{$\begin{array}{l}\text { Perception of } \\
\text { management }\end{array}$} \\
\hline Unit & 6 & 0.79 & 50 & 47.02 & 35.5 \\
\hline Hospital & 4 & 0.75 & 50 & 49.67 & 33.9 \\
\hline $\begin{array}{l}\text { Working } \\
\text { conditions }\end{array}$ & 3 & 0.65 & 50 & 54.69 & 34.8 \\
\hline
\end{tabular}


The intercorrelation factor of the customized version of the SAQ for Brazil was moderate to strong. The correlation of each domain with the total ranged from
0.70 to 0.78 , except for the domain of Stress Recognition, which showed negative correlations and a low item-total correlation (Table 3).

Table 3 - Pearson correlation coefficient between the domains of the Safety Attitudes Questionnaire - Portuguese version. Brazil, 2011

\begin{tabular}{|c|c|c|c|c|c|c|c|c|}
\hline & $\begin{array}{l}\text { Teamwork } \\
\text { climate }\end{array}$ & $\begin{array}{l}\text { Safety } \\
\text { Climate }\end{array}$ & $\begin{array}{c}\text { Job } \\
\text { Satisfaction }\end{array}$ & $\begin{array}{l}\text { Perception of } \\
\text { management of } \\
\text { the Hospital }\end{array}$ & $\begin{array}{l}\text { Perception of } \\
\text { management of } \\
\text { the Unit }\end{array}$ & $\begin{array}{l}\text { Working } \\
\text { conditions }\end{array}$ & $\begin{array}{l}\text { Stress } \\
\text { recognition }\end{array}$ & $\begin{array}{l}\text { SAQ } \\
\text { total }\end{array}$ \\
\hline Teamwork climate & 1 & 0.62 & 0.49 & 0.36 & 0.44 & 0.45 & -0.03 & 0.72 \\
\hline Safety Climate & 0.63 & 1 & 0.49 & 0.43 & 0.49 & 0.47 & -0.04 & 0.78 \\
\hline Job Satisfaction & 0.49 & 0.49 & 1 & 0.40 & 0.43 & 0.46 & -0.13 & 0.70 \\
\hline $\begin{array}{l}\text { Perception of management } \\
\text { of the Hospital }\end{array}$ & 0.36 & 0.42 & 0.39 & 1 & 0.55 & 0.45 & -0.03 & 0.70 \\
\hline $\begin{array}{l}\text { Perception of management } \\
\text { of the Unit }\end{array}$ & 0.44 & 0.49 & 0.43 & 0.55 & 1 & 0.54 & -0.00 & 0.77 \\
\hline Working conditions & 0.45 & 0.46 & 0.46 & 0.45 & 0.54 & 1 & -0.08 & 0.70 \\
\hline Stress recognition & -0.03 & -0.04 & -0.13 & -0.03 & -0.00 & -0.08 & 1 & 0.15 \\
\hline SAQ total & 0.74 & 0.78 & 0.68 & 0.70 & 0.80 & 0.70 & 0.13 & 1 \\
\hline
\end{tabular}

The construct validity of the SAQ version adapted to Brazil was assessed through an exploratory, confirmatory factor and comparison analysis between different groups.

Exploratory factor analysis of the SAQ adapted version was performed through Varimax rotation matrix for the components of Teamwork Climate, Safety Climate, Job Satisfaction, Perception of Hospital Management, Perceptions of Unit Management, Working Conditions and Stress Recognition, using 41 items.

According to the correlation matrix of the nine components, we observed that the first component grouped the items from the domain Teamwork Climate and Safety Climate. The second component grouped the items related to the domain Job Satisfaction. The third component is related to the items of the domain Perception of Management of the Unit. The fourth component grouped the items of the domain Perception of Management of the Hospital and item 14, which the author of the SAQ had not allocated to any domain initially. The fifth component grouped the items related to the domain Stress Recognition. The sixth component grouped the items related to the domain Working Conditions. The seventh component grouped items 33, 34 and 35, which were not allocated to any domain either. The eighth component grouped two items, which in the original instrument belonged to the domain Perception of Management. The ninth component grouped the reverse items of the instrument, 2, 11 and 36. Nine components were identified. Each of the nine components coincided with the questions specific to each area, according to the original scale. However, some differences were found, namely: the first component divided the areas of Teamwork Climate and Safety Climate. Question 14, "My suggestions about safety would be acted upon if I expressed them to management" was allocated to the domain Perception of Hospital Management. This question is not part of any domain, however, based on the correlation values of the exploratory factor analysis and the semantic aspect of this question, the decision was made to allocate it in the domain of Perception of the Hospital Management.

Confirmatory factor analysis, adjusting the final 41item model, was satisfactory. The total scale yielded the following indexes: Bentler Comparative Fit Index of 0.98, Goodness of fit index (GFI) 0.92, Adjusted Goodness of fit index (AGFI) of 0.9 and Root Mean Square Error of Approximation (RMSEA) 0.04 .

Finally, the following hypotheses were confirmed through the method of group comparison, another type of construct validation: (1) There is no difference in SAQ scores between male and female professionals. (2) There is a difference in the levels of the instrument scores among hospitals. (3) There is no difference between the scores of participants with a high school diploma and those with higher education. (4) There is no difference in participants' scores according to the time of experience.

We consider the following variables in the division of the groups: gender, education, hospitals and work experience.

We confirmed all hypotheses, since the perception of the safety climate did not depend on the professionals' gender and level of training. A difference between perceptions of safety climate was expected, though, according to the hospital and length of experience. It is natural that the professionals' perception of safety climate differs among hospitals, and also according to the professionals' experience, since it is assumed that professionals with less time at the unit tend to evaluate the institution that had just admitted them positively. 


\section{Discussion}

With regard to the reliability analysis, our results showed that the version adapted to Portuguese presented a total Cronbach's alpha of 0.89 . This ratio ranged from 0.65 to 0.79 among the areas. Similar values were obtained in other validation studies of the SAQ in Norway, where Cronbach's alpha ranged from 0.68 to 0.85 ; in China, where the coefficient figured between 0.79 and 0.9 ; in Switzerland, between 0.72 and 0.89 ; and in the U.S., between 0.65 and $0.88^{(10-13)}$. According to literature, these values show acceptable internal consistency among the instrument items ${ }^{(14)}$.

The areas Teamwork Climate (alpha 0.65), Safety Climate (alpha 0.67) and Working Conditions (alpha 0.65), however, presented Cronbach's alpha coefficients below 0.70 , indicating low correlation among items. A sample size similar to ours (1306 professionals) most closely approached the internal consistency levels found in the SAQ version adapted to Brazil, with alpha coefficients of 0.68 and 0.71 for Teamwork Climate and Working Conditions, respectively ${ }^{(10)}$.

Cronbach's alpha is a coefficient we rely on to confirm the instrument's reliability. Only the repeated use of the instrument in different samples can indicate its validity and reliability though. Only a scale that repeatedly generates reliable data can be considered reliable with greater certainty ${ }^{(15)}$.

Moderate to strong correlation between domains was observed for the adapted version of the SAQ. The itemtotal correlation ranged between 0.70 and 0.78 , except in the domain of Stress Recognition, which showed low correlation coefficients. These results have also been identified by the authors of the questionnaire ${ }^{(3)}$ and for the version of the instrument translated and validated for Sweden ${ }^{(12)}$. This negative correlation is expected because, the higher the perceived stress, the lower the total score of the questionnaire should be.

Item-domain correlation analysis showed mostly positive and significant moderate to strong coefficients, except for the reverse questions 2 and 11 . When removed, these questions increase the Cronbach's alpha of their respective domains, Teamwork Climate (alpha 0.69) and Safety Climate (alpha 0.68).

As the authors conducted exploratory factor analysis, this did not have to be repeated in this study. However, as questions 14 and 33 to 36 were added after the tests the authors conducted, exploratory analysis was necessary to identify in what areas these questions would obtain a better correlation coefficient. Item 14 was allocated to the domain Perception of Management of the Hospital and items 33 to 35 , which had not been allocated to any domain either, were allocated to a unique component, with the suggested name Safe Behavior/ Safe Practices. Question 14, which does not belong to any domain, will be included in the domain Perception of Management in the SAQ version adapted to Portuguese.

Confirmatory factor analysis, adjusting the final 41item model, was generally satisfactory and similar to the results found by the instrument authors ${ }^{(3)}$, and for the versions adapted for Norway ${ }^{(10)}$ and China(11).

\section{Conclusion}

The SAQ Brazilian version is the first valid and reliable instrument in Portuguese able to assess the safety climate in healthcare institutions. Based on this study, further research can be developed in Brazil to identify the patient safety climate in various hospital sectors, offering new perspectives to discuss this issue and pursue a better quality of health care delivery.

\section{References}

1. Colla JB, Bracken AC, Kinney LM, Weeks WB. Measuring patient safety climate: a review of surveys. Qual Safety Health Care. 2005;14(5):364-6.

2. Pronovost $\mathrm{P}$, Sexton B. Assessing safety culture: guidelines and recommendations. Qual Safety Health Care. $2005 ; 14(4): 231-3$.

3. Sexton JB, Helmreich RL, Neilands TB, Rowan K, Vella K, Boyden J, et al. The Safety Attitudes Questionnaire: psychometric properties, benchmarking data, and emerging research. BMC Health Serv Res. 2006; 44(6): 1-10.

4. Thomas EJ, Sexton JB, Helmreich RL. Discrepant attitudes about teamwork among critical care nurses and physicians. Crit Care Med. 2003;31(3):956-9.

5. Hughes-Hammer C, Martsolf D, Zoller R. Development and testing of the codependency assessment tool. Arch Psychiatr Nurs. 1998;12(5):264-72.

6. Beaton D, Bombardier C, Guillemin F, Ferraz M B. Recommendations for the cross-cultural adaptation of health status measures. American Academy of Orthopedic Surgeons Institute for Work \& Health. 2002. [acesso 14 abr 2009]. Disponível em: http://www.dash.iwh.on.ca/ assets/images/pdfs/xculture2002.pdf.

7. Pasquali L. Psicometria - Teoria dos testes na psicologia e na educação. 3ed. Rio de Janeiro: Vozes; 2003. 397 p. 8. Tabachnick BG, Fidell L S. Using Multivariate Statistics. 5th ed. Boston: Allyn and Bacon; 2007. 1008 p.

9. Cohen J, Cohen P. Applied multiple regression correlation analysis for the behavioural sciences. 2nd ed. Hillsdale, NJ: Lawrence Erbaum; 1983. 541 p. 
10. Deilkas ET, Hofoss D. Psychometric properties of the Norwegian version of the Safety Attitudes Questionnaire (SAQ), Generic Version (Short Form 2006). BMC Health Serv Res. 2008;22(8):191.

11. Lee WC, Wung HY, Liao HH, Lo CM, Chang FL, Wang PA, et al. Hospital safety culture in Taiwan: a nationwide survey using Chinese version safety attitude questionnaire. BMC Health Serv Res. 2010;10(10):234.

12. Nordén-Hägg A, Sexton JB, Kälvemark-Sporrong S, Ring L, Kettis-Lindblad A. Assessing Safety Culture in Pharmacies: The psychometric validation of the Safety Attitudes Questionnaire (SAQ) in a national sample of community pharmacies in Sweden. Clin Pharmacol. 2010;10(8):1-12.

13. Patterson PD, Huang DT, Fairbanks RJ, Wang HE. The Emergency Medical Services Safety Attitudes Questionnaire. Am J Med Qual. 2001;25(2):109-15.

14. Terwee $C B$, Bot $S D$, de Boer $M R$, van der Windt $D A$, Knol DL, Dekker J, Bouter LM, et al. Quality criteria were proposed for measurement properties of health status questionnaires. J Clin Epidemiol. 2007;60(1):34-4.

15. Maroco J, Garcia-Marques T. Qual a fiabilidade do alfa de Cronbach? Questões antigas e soluções modernas? Lab Psicol. 2006;4(1):65-90. 